\title{
Movimientos sociales e institucionalización: la especificidad de los movimientos socioterritoriales
}

Fernanda Torres

IdIHCS - UNLP/CONICET

Recibido: 4 de noviembre de 2019. Aceptado: 10 de febrero de 2020.

\begin{abstract}
Resumen
El presente trabajo se propone analizar los procesos de institucionalización que llevan adelante ciertos movimientos sociales específicos: los movimientos sociales que se apropian de un espacio para el desarrollo de sus proyectos políticos, definidos como movimientos socioterritoriales. Revisar el debate en relación con los riesgos y posibilidades que la institucionalización ofrece a los procesos de movilización, politización y transformación social que protagonizan los movimientos sociales supone, en el caso de los movimientos socioterritoriales, el análisis de sus territorios. Porque es a partir de ellos que desarrollan su estrategia, constituyen su identidad y sociabilidad política y, también, sus instituciones. De allí que proponemos un acercamiento espacial, bajo una estrategia cualitativa, para repensar la idea de instituciones y de ciudadanía a partir del análisis de las instituciones territorializadas de un caso de movimiento socioterritorial urbano, la Organización Barrial Tupac Amaru en Jujuy, Argentina.
\end{abstract}

PALABRAS CLAVE: MOVIMIENTOS SOCIOTERRITORIALES. INSTITUCIONES. CIUDADANÍA. ORGANIZACIÓN BARRIAL TUPAC AMARU.

\section{Social movements and institutionalization: the specificity of socioterritorial movements}

\begin{abstract}
The main objective of this paper is to analyze the processes of institutionalization carried out by specific social movements: social movements that appropriate a space for the development of their political projects, defined as socioterritorial movements. Reviewing the debate around the risks and possibilities offered by institutionalization to the processes of mobilization, politicization and social transformation carried out by social movements supposes, in the case of socioterritorial movements, the analysis of their territories. Because those territories are from which they develop their strategy, constitute their identity and political sociability and, also, their institutions. Hence, we propose a spatial approach to rethink the idea of institutions and citizenship, from the analysis, under a
\end{abstract}


Movimientos sociales e institucionalización: la especificidad de... FERNANDA TORRES

qualitative strategy, of the territorialized institutions of a case of urban socioterritorial movement, the Tupac Amaru Neighborhood Organization in Jujuy, Argentina.

KEYWORDS: SOCIOTERRITORIAL MOVEMENTS. INSTITUTIONS. CITIZENSHIP. NEIGHBORHOOD ORGANIZATION TUPAC AMARU.

PALAVRAS-CHAVE: MOVIMENTOS SOCIOTERRITORIAIS. INSTITUIÇÕES. CIDADANIA. ORGANIZAÇÃO DO BAIRRO TUPAC AMARU.

\section{Introducción}

Dentro del campo de estudios sobre los movimientos sociales se ha dado un debate específico, nunca del todo saldado, en torno a las posibilidades, riesgos y transformaciones que supone para los movimientos protagonizar procesos de institucionalización. Desde Offe (1992), pasando por Tilly (2010) y Tarrow (1997), todos ellos han señalado la distinción entre el accionar de los movimientos sociales dentro del campo de la política no institucional y el camino de la profesionalización e institucionalización que los lleva a convertirse en partidos políticos o sindicatos.

Consideramos necesario revisitar este debate, incorporando literatura producida en América Latina, donde la distinción entre política institucional y política no institucional es menos clara (O’Donnell, 1997; Tapia, 2008), y analizando ciertos casos de movimientos sociales, que desarrollan una estrategia, identidad, sociabilidad e institucionalidad ligada a la construcción de territorios propios: los movimientos socioterritoriales (Halvorsen et al., 2019).

El recorrido supone, entonces, comenzar discutiendo las definiciones de los conceptos territorio, instituciones y movimiento socioterritorial. Para este último, incorporamos la discusión en torno a cuatro ejes: estrategia, identidad, sociabilidad política e instituciones (Autor et al., 2019); para luego abocarnos a esta última dimensión y sus vinculaciones en pos de comprender los movimientos sociales y la especificidad que revisten los socioterritoriales en relación con sus procesos de institucionalización/ desinstitucionalización y territorialización/desterritorialización. ${ }^{1}$

Por último, proponemos un acercamiento espacial para repensar la idea de ciudadanía retomando la propuesta de Holston (2009) con relación al análisis de un nuevo tipo de ciudadanía, la ciudadanía urbana, cuyos derechos se distribuyen ya no a partir de la pertenencia formal al Estado, sino en base al ejercicio mismo de la práctica política en la ciudad.

Analizaremos la manera mediante la cual un movimiento urbano que caracterizamos como movimiento socioterritorial, la Organización Barrial Tupac Amaru de Jujuy, fue protagonista de un proceso de desarrollo institucional en una porción del territorio urbano de la ciudad de San Salvador de Jujuy, concibiendo prácticas que pueden ser entendidas como formadoras de ciudadanías territorializadas.

1 Los llamados procesos geográficos de territorialización/desterritorialización y reterritorialización (T-D-R) configuran una manera de comprender el territorio en su dinámica de construcción y transformación. Es preciso recordar que la primera relectura geográfica de la idea original de Deleuze y Guattari (2002), referida al proceso de T-D-R, fue realizada por Raffestin (1993), quien propuso pensar dichos procesos en base al grado de accesibilidad a la información. El acceso (o no) a esta, los símbolos y los nuevos significados construidos pueden favorecer nuevos territorios (territorialización), destruirlos (desterritorialización) o reconstruirlos (reterritorialización). Esta primera mirada será posteriormente reproblematizada a la luz del análisis de los movimientos sociales desde la geografía, tema que abordaremos más adelante. 
Movimientos sociales e institucionalización: la especificidad de... FERNANDA TORRES

Nos apoyaremos en una investigación empírica, bajo una aproximación metodológica cualitativa, realizada durante cuatro estancias de investigación en la ciudad de San Salvador de Jujuy en 2015 y 2016. Durante dichas estancias efectuamos jornadas de observación participante y no participante en diferentes acciones y prácticas de la organización (laborales, educativas, de salud, culturales, asistenciales, políticas, organizativas), en diversos barrios de vivienda construidos por la organización, especialmente en el barrio de la Tupac Amaru en Alto Comedero, también en la sede de la organización en el centro de la ciudad de San Salvador de Jujuy y durante acciones extraordinarias como asambleas y movilizaciones. ${ }^{2}$

\section{Territorio, instituciones y movimientos socioterritoriales}

Las instituciones son una mediación entre la sociedad civil y el régimen político, de tal modo que puedan ser redefinidas las formas de participación y los dispositivos de legitimación que conforman una comunidad política (O’Donnell, 1997). Al ampliar la perspectiva de análisis, la institucionalización no queda reducida al espacio de lo estatal, sino que es posible pensarla como estabilización o como establecimiento de ciertas regularidades, pautas comunes en escenarios propios de la sociedad civil, que se encuentran politizados o en proceso de politización. Los movimientos sociales, de acuerdo con Tapia (2008), no tienen un lugar específico donde hacer política, por ello pueden transitar la sociedad civil e incluso el Estado politizando los espacios sociales. El recorrido planteado en este apartado pretende desplegar las herramientas conceptuales para comprender la manera particular mediante la cual los movimientos socioterritoriales desarrollan instituciones, cómo incide en ellas el territorio, central en dichos movimientos y cómo se configura una modalidad de politización anclada en determinados territorios.

\section{Instituciones y movimientos sociales}

¿Por qué nos interesa incorporar el eje de las instituciones para comprender a los movimientos sociales? Porque detrás de esta incorporación apostamos a revisar críticamente la división entre lo social y lo político, que alude a su vez a la diferencia entre Estado y sociedad. No para desconocer sus particularidades, pero sí para postular la articulación dialéctica entre ambos espacios que habilite a comprender los momentos de conflicto y antagonismo, pero también los de consenso y acuerdo que promueven la instauración de instituciones.

O’Donnell define a la institución como un "patrón regularizado de interacción que es conocido, practicado y aceptado (si bien no necesariamente aprobado) por actores que tienen la expectativa de seguir interactuando bajo las reglas sancionadas y sostenidas por ese patrón” (1997:310).

2 Cabe aclarar que, si bien la autora del presente trabajo no es militante de la organización, sí acuerda con varios de sus objetivos e ideas, amén de que relaciones de pertenencia militante han facilitado la confianza y posibilidades de acceso al campo, pudiendo realizar observación participante en varias de las actividades que se recuperan y analizan en este artículo. Podemos apoyarnos en la propuesta defendida por Hale (2006), en torno a la investigación militante como una metodología por la cual afirmamos un compromiso político con un grupo organizado en lucha y que genera conocimientos desde, con y para este grupo. 
Movimientos sociales e institucionalización: la especificidad de... FERNANDA TORRES

Debido a ello, las instituciones configuran un proceso de generación y cristalización de pautas naturalizadas por los sujetos, que no cuestionan su existencia ni continuidad, pudiendo llegar a ser complejas organizaciones: "se supone que operan bajo reglas altamente formalizadas y explícitas, y se materializan en edificios, rituales e individuos autorizados a hablar en su nombre” (O’Donnell, 1997:310).

Es posible considerar que los sujetos pretendan, a veces, transformar las pautas de acción que orientan el abordaje de las problemáticas sociales específicas en el contexto territorial en el cual habitan, militan y/o trabajan, creando alternativas institucionales que amplíen el espectro de la participación democrática. Nos situamos, entonces, junto a quienes sostienen que las organizaciones sociales son espacios de participación política, "un espacio de experimentación democrática, cuya potencialidad no se reduce a cuestionar el orden social vigente sino también a la posibilidad de crear nuevas institucionalidades" (Natalucci y Pagliarone, 2013:77), "habilitando la creación de pautas de acción que permitan el trastocamiento de las vigentes" (Natalucci y Pagliorone, 2013:80). De esta manera, y remitiéndonos a ejemplos de movimientos sociales urbanos en Argentina, podemos considerar que las cooperativas y los bachilleratos populares del Movimiento de Ocupantes Inquilinos (MOI), la cooperativa textilera, la cooperativa de vivienda y la radio comunitaria del Movimiento Territorial de Liberación (MTL) o las propuestas educativas en los barrios de la Organización Barrial Tupac Amaru (OBTA), son ejemplos de instituciones en las escalas posibles de incumbencia de dichos movimientos, que construyen canales de mediación y representación de intereses e identidades divergentes, sobrepuestas y enredadas al ordenamiento estatal (Halvorsen, 2018).

No debemos dejar de mencionar que estas potencialidades tienen también sus riesgos. Un autor que supo graficar claramente las diferentes opciones que pueden derivar del encuentro de los movimientos sociales y la arena política es Gerardo Munck (1995), quien analiza las diversas maneras en que un movimiento social encara el desafío asociado a su orientación hacia el cambio, resultantes de la combinación de dos factores: la consistencia de la relación entre la identidad y la dimensión estratégica de un movimiento social, y la arena social o política-institucional en la cual opera. El punto de partida es el del movimiento social autorestringido, es decir, movimientos que desde la sociedad civil ensayan experimentos sociales en pequeña escala, de reafirmación de su identidad y sin ponerse en contacto con la arena política institucional; de este modo, de acuerdo con el análisis del autor, esquivan el desafío propio de los movimientos sociales que refiere a su orientación al cambio, por eso Munck denomina a dichos casos como expresiones de una estrategia netamente defensiva.

Por el contrario, los movimientos que asumen la apuesta por el cambio y desarrollan una estrategia ofensiva, se enfrentan a dos riesgos. Uno de los más frecuentes es la pérdida de autonomía, que el movimiento social se vea cooptado desde arriba, perdiendo su identidad en pos de llevar adelante su estrategia en la arena política. El segundo riesgo refiere a una situación exactamente opuesta: defendiendo su identidad, pero abandonando toda pretensión estratégica, se encuentran aquellos movimientos que privilegian objetivos no negociables y, apostando a una política pura de identidad, se vuelcan sobre sí mismos y se transforman en una fuerza social comunal o fundamentalista, ensimismada y acotada a la sociedad civil. 
Movimientos sociales e institucionalización: la especificidad de... FERNANDA TORRES

La salida planteada por el autor como la más virtuosa y coherente, atendiendo tanto a la reafirmación identitaria autónoma como a ensayar operaciones estratégicas, es la que conduce a ciertos movimientos sociales a transformarse en movimientos sociales políticamente orientados:

Así, el movimiento social mantiene una conexión consistente entre medios y fines o estrategia e identidad, pero en vez de restringir su operación a la arena de la sociedad civil, como cuando adopta una forma de acción autorrestringida, actúa tanto "dentro" como "desde" la sociedad civil donde nació. (Munck, 1995:34).

El peligro de la cooptación asociado a la pérdida de autonomía por parte de los movimientos sociales que derivan en y del debilitamiento de los rasgos identitarios de los mismos es, sin duda, el riesgo subrayado por un amplio conjunto de análisis y perspectivas en los estudios sobre el rol político de los movimientos sociales (Dinerstein et al., 2013; Reyes, 2012; Zibechi, 2008; Svampa, 2016).

Por otro lado, varios estudios han explorado cómo los movimientos sociales autónomos se han movido hacia los gobiernos y se han incorporado a ellos a través de una gama de mecanismos que van desde la concesión de nuevos derechos sociales hasta el clientelismo. El trabajo de Rossi (2017) sobre los piqueteros en Argentina es el intento más elaborado de explicar la incorporación de movimientos bajo los gobiernos kirchneristas, entendiéndola como una respuesta a la desincorporación de sectores populares bajo el neoliberalismo. Resalta que la territorialización de la política durante las décadas de 1980 y 1990 en América Latina proporcionó la base para remodelar la arena política y enfatiza la capacidad del Estado para absorber los impulsos de abajo hacia arriba.

Finalmente, hay una variedad de publicaciones que exploran la institucionalización de los movimientos sociales (López Maya, 2003; Natalucci y Pérez, 2015; Schuttenberg, 2012). Estos estudios van más allá de las críticas parciales de la institucionalización, como la pérdida de autonomía a través de la cooptación, y demuestran la importancia de lidiar con las cambiantes relaciones de movimiento-gobierno que incluyen apoyo y negociación, que a su vez forman parte de una literatura más amplia que reconoce los múltiples desafíos y dilemas de dichos procesos para la izquierda latinoamericana (Bringel y Falero, 2016).

Nuestra propuesta atiende al desafío de dejar de problematizar la institucionalización de los movimientos sociales, en cuanto intervención en la arena política formal. Tal como entendemos, ha sido el sentido preponderante de los distintos y heterogéneos estudios arriba reseñados. Por el contrario, creemos necesario incluir el análisis de otros procesos de institucionalización que configuran, desde la militancia popular, patrones, reglas e interacciones en torno a nuevas formas de articulación política. Específicamente, nos interesa poner el acento en aquellos procesos que derivan en la producción y apropiación de territorios (territorialización) por parte de los movimientos sociales y que, no siempre ni de manera inevitable, conducen a escenarios de cooptación y heteronomía.

Coincidimos con Tapia cuando habla de "la política del desborde" para describir el proceso mediante el cual, ante una demanda no cubierta por parte de los órganos institucionalizados de la política, fundamentalmente el Estado, la misma se resuelve por otras vías: "Las formas de vida política que no se organizan como parte del gobierno, se 
Movimientos sociales e institucionalización: la especificidad de... FERNANDA TORRES

organizan para disputarle y controlar ese ejercicio del poder político" (Tapia, 2008:3). En este sentido, la sociedad civil es tal como expresa el autor "otro lugar de la política"; es decir, es un espacio no estatal, que se rige con otras pautas, pero un espacio para la política al fin.

La perspectiva arriba reseñada implica, entonces, una revisión de las esferas posibles para la acción, la decisión y la participación política. Si bien el Estado ha sido el escenario privilegiado de elaboración política en las sociedades occidentales modernas, debemos reconocer que las diversas transformaciones que fueron complejizando el alcance y las derivaciones de las actividades políticas han ampliado esos lugares predilectos para la política, sobre todo de la mano de los procesos de ciudadanización: la ampliación de la condición y el contenido del rol de la ciudadanía.

La definición hegemónica de ciudadanía que rige en la mayoría de los Estados democráticos occidentales es la que nos legó la tradición liberal: "La ciudadanía es un status que se otorga a los que son miembros de pleno derecho de una comunidad. Todos los que poseen ese status son iguales en lo que se refiere a los derechos y deberes que implica" (Marshall, 1997:312). Es decir, la ciudadanía refiere a un status que deriva en un conjunto de derechos, histórica y geográficamente definidos, pero bajo una pretensión universalista: todos los miembros de una comunidad política gozan de iguales derechos y deberes. Entre otros debates que suscita dicha definición y su derivación institucional, nos interesa aquí subrayar que dicha concepción invisibiliza un aspecto considerado por muchos como central: el carácter sustantivo de la ciudadanía entendida como participación; entendemos, junto con Giovanna Procacci (1999), que la ciudadanía es política porque responde a una estrategia de crear ciudadanos por medio de un conjunto de prácticas y conocimientos.

Por su parte, García Linera enfatiza el necesario ejercicio práctico de las prerrogativas propias del ciudadano en pos de la reinvención de lo público:

(...) esta democracia de ciudadanía no es un problema de legalización de derechos otorgados a la población por el Estado, aunque sea la manera de su objetivación institucional; solo hay democracia en cuanto hay sujetos que producen intersubjetivamente prerrogativas y facultades como ampliación de su responsabilidad en la definición de lo público. (García Linera, 2016:36-37).

Podemos decir, entonces, que la ciudadanía no solo es una prédica y un conjunto de regulaciones, sino que también es una práctica y una construcción activa, que para analizar dicha práctica debemos atender a los procesos colectivos de construcción de ciudadanía y no limitarnos a las individualidades. Puesto que el estatus individual y universal que predica la ciudadanía en su sentido formal, sabemos que se traduce en articulaciones colectivas no universales a la hora de pensar esas otras institucionalizaciones ancladas en la desmonopolización del poder político.

En este sentido es que vinculamos las acciones, propuestas e iniciativas por parte de los movimientos y actores colectivos que organizan prácticas de ciudadanía participativa a través de una institucionalidad particular, es decir, por fuera de los canales sistémicos asociados a los partidos políticos (representación política formal) y los grupos de interés (representación funcional). 
Movimientos sociales e institucionalización: la especificidad de... FERNANDA TORRES

Retomando a Melucci (1986) consideramos que los movimientos sociales luchan no solo por la reapropiación de la estructura material de la producción, sino también por el control colectivo del tiempo, del espacio y de las relaciones de la vida cotidiana. Específicamente, en relación con el control colectivo del espacio es que involucramos el análisis de los movimientos socioterritoriales como agentes que ejercitan otros procesos de ciudadanización en los territorios apropiados por ellos, porque en esos territorios se desarrolla una sociabilidad política propia que conlleva una representación territorial, que excede o plantea otro circuito (Vite, 2005) de la ciudadanía representativa liberal, ya no política o funcional, sino territorial. De allí la importancia, entonces, de definir el concepto territorio.

\section{Territorio}

En 1980 el geógrafo Claude Raffestin publica Por una geografía del poder en donde, considerando el pensamiento de Foucault, sostiene que:

(...) [el] poder no se adquiere; es ejercido a partir de innumerables puntos... [Las] relaciones de poder no están en posición de exterioridad con respecto a otros tipos de relaciones (económicas, sociales, etc.), pero son inmanentes a ellas. (Raffestin, 1993:53).

El territorio se entiende como la manifestación espacial del poder fundamentada en relaciones sociales determinadas, en diferentes grados, por la presencia de energía acciones y estructuras concretas- $\mathrm{y}$ de información -acciones y estructuras simbólicas-.

El territorio refiere a un proceso dinámico y relacional que se entiende más allá de las formas modernas y las relaciones de poder del $\mathrm{E}^{\mathrm{o}}$ stado soberano (Elden, 2013). Fernandes Mançano (2005), en línea con otros académicos latinoamericanos contemporáneos (por ejemplo, Haesbaert, 2004; Manzanal et al., 2007; Schneider y Tartaruga, 2006; Souza 2001), se basa en un conjunto heterodoxo de teóricos como Lefebvre (2013), Raffestin (1993) y Milton Santos (1996) para definir el territorio como "espacio apropiado por una determinada relación social que lo produce y lo mantiene a través de una forma de poder" (Fernandes Mançano, 2005:27).

Marcelo Lopes de Souza, en la misma sintonía, refiere al territorio como "un espacio definido y delimitado por y a partir de relaciones de poder" (2001:78). Pudiendo este estar asociado tanto a formas jurídico-políticas (ejemplo clásico de un Estado), culturales (en el caso de una asociación barrial dentro de una ciudad) y/o económicas (en el caso de una empresa). Plantea atributos de multiescalaridad y flexibilidad espacial y temporal para comprender los diversos territorios. Se trata de un autor que articula desde la geografía muchos de los debates clásicos anteriormente reseñados en torno a los movimientos sociales. Por dar solo un ejemplo, introduce la perspectiva espacial en las discusiones sobre autonomía:

(...) la autonomía no es sólo redescubierta y "reinventada" como núcleo de un proyecto político-social también es "espacializada" de una manera que la literatura político-filosófica no sabe o no puede realizar (...) La praxis de los movimientos contemporáneos ha demostrado que el cambio social concreto tiene que ser un cambio socio-espacial, comenzando por el trabajo de movilización y organización a escala (micro) local. (Souza, 2011:76). 
Movimientos sociales e institucionalización: la especificidad de... FERNANDA TORRES

Fernandes plantea la necesidad de sumar el análisis geográfico para la comprensión de los movimientos sociales, es decir, subraya la importancia de incorporar una lectura específicamente geográfica de los movimientos sociales y sus elementos. De este autor tomaremos la propuesta de pensar en la especificidad de aquellos movimientos que tienen al territorio como su objetivo central y determinante: los movimientos socioterritoriales.

\section{Movimientos socioterritoriales}

Analizando el recorrido protagonizado por ciertos movimientos sociales pueden ser identificadas experiencias y sentidos que han ido cobrando un profundo carácter institucional, si por ellos entendemos la sistematización de prácticas, reglas de interacción y normas, más o menos explícitas, que regulan comportamientos y transacciones en un espacio determinado, construido como un territorio. Territorio donde se despliegan identidades, redes, modalidades de sociabilidad y estrategias.

Nos referimos a los procesos de territorialización que, tal como ya ha sido señalado, implican nuevas configuraciones espaciales, construidas en pos de un proyecto político. Entendemos como socioterritoriales a aquellos movimientos sociales que, entonces, transforman el espacio en territorio a través de la conflictualidad entre las fuerzas políticas que intentan crear, conquistar y controlar sus territorios (Fernandes, 2005). Proponemos su análisis basado en cuatro ejes: control y apropiación del espacio como estrategia; identidades y demandas vinculadas al territorio; visibilización y politización de la reproducción social e institucionalización socioterritorial, siendo este último el eje central del presente trabajo.

La estrategia refiere a la forma mediante la cual los movimientos sociales resuelven su coordinación para la consecución de sus objetivos, y puede asumir diversas modalidades. En el caso de los movimientos socioterritoriales, es decir, aquellos movimientos que se apropian, a través de sus prácticas e ideas (energía e información, de acuerdo con Raffestin, 1993), de un espacio para lograr sus proyectos, su estrategia se fundamenta en la sustentación de dicha apropiación, ergo en sus territorios.

La identidad colectiva -referencias, experiencias, significados, redes de pertenencia y de definición que construyen los movimientos sociales- posee, en el caso de los movimientos socioterritoriales, un fuerte ligamiento de sentido en el territorio. A partir del territorio se construye la identidad y la subjetividad política en los movimientos socioterritoriales, generando tanto las oportunidades como las limitaciones para su potencial de movilización.

De la mano de lo anterior, la socialización política, que permite a los movimientos generar nuevos valores y nuevas relaciones sociales, tiene en los lugares de encuentro y definiciones territoriales su fuente principal. Para los movimientos socioterritoriales el territorio es el objeto central de su lucha y es la clave para sus fines y necesidades y, si bien, inevitablemente, comprometen territorios dominados por el Estado, están principalmente orientados a transformar las relaciones socioespaciales mediante el control político de un determinado espacio.

Finalmente, entonces, los procesos de territorialización, desterritorialización y reterritorialización (TDR) son la clave para entender la manera mediante la cual los movimientos 
socioterritoriales institucionalizan sus formas organizacionales, a la vez que se superponen y se enredan con el proyecto territorial del Estado.

Los movimientos socioterritoriales tienden a construir instituciones en y a través del territorio, proveyendo herramientas a través de las cuales resolver sus objetivos. Hablar de institucionalización en los casos de movimientos socioterritoriales, corriéndose de posturas normativas que piensan en clave de cooptación, puede problematizarse bajo una peculiar modalidad que refiere a dicho proceso a través de construcción de territorios:

La expansión y/ o creación de territorios son acciones representadas por la desterritorialización. Ese movimiento explicita la conflictualidad y las contradicciones de las relaciones socioespaciales y socioterritoriales. Debido a esas características, ocurre al mismo tiempo la expansión y la destrucción; la creación y el reflujo. Ese es el movimiento del proceso geográfico conocido como TDR, o territorialización -desterritorialización- reterritorialización. (Fernandes, 2005:5).

Las ideas sumamente influyentes de Santos $(1985,1996)$ son pertinentes al señalar que en los territorios se dan luchas que abren oportunidades centradas en la búsqueda e implementación de otras regulaciones, otras instituciones propias de cada lugar. El autor afirma que el conflicto entre las normas hegemónicas y las nuevas normas por las que se lucha "(...) debe ser hoy un dato fundamental del análisis geográfico" (Santos, 1996:128). Si analizamos la construcción de nuevas normas, en cuanto caminos propositivos que se configuran en nuevas instituciones, es claro que la construcción de territorios conlleva la producción de instituciones que garanticen las relaciones de poder de dicha apropiación. De ahí que proponemos, como retomaremos más adelante, hablar de ciudadanías territorializadas por los movimientos que se apropian de un espacio para el desarrollo de sus proyectos políticos.

Nos abocaremos al estudio de ciertos movimientos socioterritoriales urbanos que disputan la ciudad a partir de producciones de hábitat urbano que no se condicen con los procesos de urbanización propios del capital y sus agentes inmobiliarios hegemónicos. Este tipo de esquema puede observarse en Argentina, como ya ha sido mencionado, en diversos casos y localizaciones. El análisis que sigue retomará los resultados de nuestra investigación realizada sobre la OBTA en Jujuy ${ }^{3}$ con el fin de iluminar los procesos

3 Fueron realizadas entrevistas, entrevistas en profundidad y/o conversaciones informales con: presidentes de cooperativas de OBTA-San Salvador; responsables y delegados/as de copas de leche; asesores legislativos de Frente Unidos y Organizados (FUyO) - alianza electoral de la que participa la OBTA-; directores de instituciones educativas y asesor legislativo; responsable de área de administración; responsable de los talleres de formación profesional; responsables de área contable; trabajadores/as de las instituciones escolares (docentes y no docentes); abogados/as de la OBTA; miembros del grupo de género, trabajadores de la Sede de la OBTA. Se realizó observación participante y no participante de: una asamblea general de la OBTA (de todas las sedes de la provincia, realizada en el edificio del colegio secundario y del terciario de la OBTA, S.S. de Jujuy); almuerzo en la sede de algunos de los delegados luego de la asamblea; movilización al Ministerio de Tierras para reclamar la obtención de escrituras para las casas de la OBTA; reunión con funcionario del Ministerio y comisión para llevar adelante las escrituras; realización de un relevamiento en el barrio Alto Comedero de S.S. de Jujuy, visita casa por casa para conocer la situación y recopilar los papeles necesarios. También se desarrolló observación participante de la asamblea de delegados S.S. de Jujuy; una jornada de trabajo en la obra de construcción del edificio de la escuela, Barrio Alto Comedero; jornada de entrega de mercadería, guardapolvos, calzado y un monto de dinero en efectivo a todos los afiliados de capital de la OBTA (galpón recuperado, SS de Jujuy); radio abierta de Radio Pachamama con intervenciones de campaña electoral (galpón recuperado, SS de Jujuy); sesión de la Legislatura Provincial en S.S. de Jujuy, en la cual participaron tres de los cuatro diputados que tiene el partido FUyO, el sector de trabajo de los asesores de los bloques, junto con 
Movimientos sociales e institucionalización: la especificidad de... FERNANDA TORRES

que refieren a la construcción colectiva de instituciones territorializadas que habilitan procesos de ciudadanización particulares, anclados en una modalidad territorial.

\section{Instituciones de movimientos socioterritoriales urbanos: el caso de la Tupac}

La forma de acceso al suelo y la vivienda urbana por parte de sectores medios y bajos en América Latina, de acuerdo con Pedro Abramo (2003), se resuelve mediante tres lógicas distinguibles de acción social. La primera lógica refiere a la acción del Estado, que supone la imposición de la decisión oficial en torno a la distribución, selección y modalidad de acceso y usufructo del suelo urbano, que garantice el mayor grado de bienestar social, sobre las voluntades de los individuos de la sociedad civil. La segunda es la lógica del mercado, según la cual se consolida un espacio donde se encuentran los ofertantes y demandantes de suelo urbano para dirimir su intercambio, pudiendo estar este sujeto a las normas jurídicas y urbanísticas, o no (mercado inmobiliario formal o informal, respectivamente). Por último, identifica la lógica de la necesidad, relacionada con las motivaciones originadas en la pobreza, en la carencia de capitales tanto económicos como institucionales y políticos que redunda en procesos de acciones colectivas, con ocupación de tierras.

Podemos aseverar que la gran desigualdad social que caracteriza las sociedades en América Latina, y la Argentina no es la excepción, tiene su correlato indiscutible en una pronunciada desigualdad urbana. El complejo debate sobre la problemática urbana no será recuperado aquí, por no representar el eje analítico del presente artículo, pero podemos mencionar otros trabajos en los cuales nos hemos ocupado de su importancia y su problematización para comprender el caso de la OBTA. En dichos trabajos (Torres, 2016, 2018), hemos expresado que la lógica para resolver el acceso a la vivienda urbana, que llevó adelante OBTA en la provincia de Jujuy, se desarrolló bajo una modalidad mixta: combinando la lógica de la necesidad y la lógica del Estado. Configurando un proceso de producción de hábitat popular, por parte de una organización social y política que protagonizó procesos territoriales de construcción colectiva de hábitat urbano, en clara oposición a la lógica del mercado. Sin embargo, la superposición con las reglas y prerrogativas estatales, así como la debilidad institucional de los propios logros, resultaron en un proceso contradictorio que no pudo evitar reproducir ciertas dinámicas propias de la ciudad informal.

En los primeros momentos, por darte un ejemplo, era difícil conseguir un plan o una cooperativa, entonces eso llevaba a la marcha, a la confrontación, a la lucha. Pero después llegó un momento en el que se propició, creo, el espacio, con el cambio de gobierno cuando asumió Cristina... porque con Kirchner más o menos hubo que demostrarle que uno quería trabajar... con Cristina, es como que de alguna manera ya habíamos demostrado los primeros años entonces es como que no había que seguir. Y era en ese momento donde la organización tendría que haber apostado a decir: vamos a fortalecer nuestras instituciones.

los asesores del bloque del FUyO; jornadas de campaña electoral; jornadas de trabajo en el terciario en la sede del OBTA en S.S. de Jujuy. El material secundario relevado incluyó la lectura de diverso material publicado por la OBTA (anuario 15 años, videos de difusión de sus trabajos y emprendimientos). 
Movimientos sociales e institucionalización: la especificidad de... FERNANDA TORRES

Vamos a fortalecer nuestras fábricas, vamos a fortalecernos a nosotros en este crecimiento. (Jorge, responsable de los talleres de formación profesional. Galpón recuperado de la vieja estación, S.S. de Jujuy. Octubre de 2015).

Si bien no puede plantearse como un caso generalizable, sí es posible decir que delinea un camino compartido por diversas experiencias organizativas que se alejan del concepto de movimiento social urbano tal como fue definido por Castells (1986), entre otros motivos, por representar procesos de acción colectiva y transformación en los cuales el Estado ha sido sobredeterminante (Shetman, 2009).

En Argentina, diversos autores han demostrado que, en contextos de crecimiento de las clases trabajadoras urbanas excluidas social y políticamente durante el período postindustrial, particularmente durante el gobierno neoliberal del presidente Carlos Menem (1989-1999), la producción social del territorio urbano, en la forma del barrio, fue central para la generación de nuevas subjetividades y formas de organización política durante la década de 1990 y la primera década de los 2000 (Merklen, 2005; Grimson, Ferraudi y Segura, 2008). Tras la elección de los gobiernos llamados de centro izquierda o progresistas de Néstor y Cristina Kirchner (2003-2015), algunos movimientos vieron una oportunidad política desde abajo, y fueron seducidos desde arriba, a territorializar sus luchas dentro del Estado argentino, a través de la inclusión en las iniciativas de formulación de políticas y ciertas estructuras de gobierno, lo que redundó en el inicio de un proceso complejo y contradictorio de institucionalización de ciudadanías, en ciertos casos territorializadas.

Las definidas como lógicas mixtas de producción del hábitat, permiten conocer y analizar las múltiples contradicciones en el camino por lograr ciudades más inclusivas y con mayor equidad, desde experiencias que efectivamente en su desarrollo construyen nuevas subjetividades y formas organizativas populares, pero con límites y dificultades a la hora de tramitar su inscripción institucional. Consideramos que el análisis de ciertos movimientos socioterritoriales urbanos, y sus acciones en pos de disputar el modelo de ciudad, permiten iluminar el complejo proceso de construcción de instituciones territoriales.

\section{La Tupac y sus instituciones territoriales}

La OBTA, nacida en 1999 en Jujuy, al calor de las luchas contra las políticas neoliberales del momento, se desarrolló durante los gobiernos kirchneristas bajo una estrategia de terrritorialización de su identidad, su sociabilidad y sus instituciones.

A la par que crecían sus viviendas y sus barrios, crecía la organización y su poder. Un poder territorialmente definido. La estrategia, la identidad, la sociabilidad y las instituciones de la OBTA eran territoriales.

El ejemplo más paradigmático de este proceso es el Barrio de la Tupac en Alto Comedero, en San Salvador de Jujuy, ${ }^{4}$ donde la organización alcanzó a construir 3000 viviendas

4 La ciudad de San Salvador de Jujuy, ciudad capital de la provincia con 231.229 habitantes, representa el $37.8 \%$ de la población de Jujuy, formando junto con las vecinas localidades de Palpalá y Yala un aglomerado (Gran San Salvador de Jujuy) de 278.336 habitantes (45.5 \% de la población provincial). Supone un centro de atracción de población por las esperanzas cifradas en torno a la obtención de empleo, posibilidades 
(Figura 1). Es un claro proceso de territorialización, mediante el cual la OBTA se apropió de una porción del territorio urbano, determinó su uso, sus reglas, sus posibilidades y construyó identidad, poder y estrategia política a partir de allí.

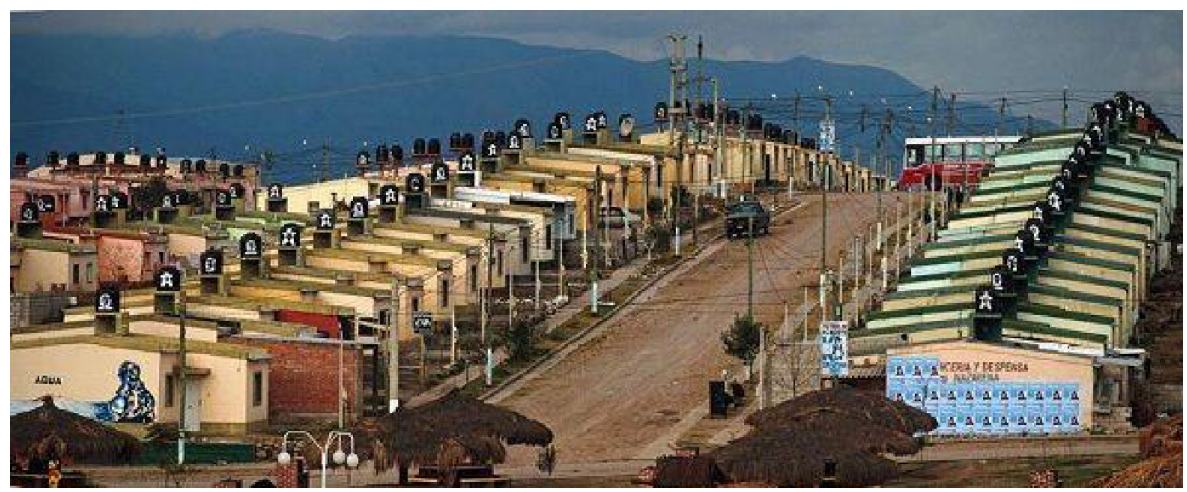

Figura 1. Barrio de la Organización Barrial Tupac Amaru en Alto Comedero, S. S. de Jujuy. Fuente: http://www.taringa.net/post/imagenes/13364422/Fotos-del-barrio-Tupac-Amaru--S-S-de-Jujuy. html

En primer lugar, la principal estrategia de visibilización de la organización se concibió a partir del territorio construido en la ciudad, donde los, cada vez más numerosos, miembros de la Tupac pudiesen vivir y cubrir sus necesidades. En y desde este nuevo territorio, reprodujeron modos de convivir, distribuir y pautar los intercambios e interacciones sociales, ya sea en el campo de la educación, del trabajo, de la salud, de la cultura.

En todos los espacios de la organización los cómo, los dónde y los cuándo de las actividades y sus reglas se construyeron colectivamente y con pautas propias: todos los miembros de la Tupac participaban de alguna copa de leche al afiliarse a la organización, con la que tenían que colaborar con trabajo voluntario o cualquier otro tipo de ayuda; todos los niños y niñas accedían a la escuela, la secundaria y el terciario de manera gratuita y con trayectorias flexibles; todos los que necesitaban asistencia médica podían obtenerla de manera gratuita en los centros de atención de la organización, sin transitar los canales formales de trámites y autorizaciones habituales de las obras sociales, ni padecer las largas esperas del saturado sistema público de salud. Los problemas, los conflictos y tensiones entre vecinos de los barrios de la Tupac o entre trabajadores de una misma cooperativa se resolvían en asamblea, incorporando en la discusión al presidente de la cooperativa o, incluso, a la máxima referente de la organización, Milagro Sala.

educativas y disponibilidad de recursos estatales que no llegan a los diversos rincones de la provincia. Sin embargo, y tal como se repite en la mayoría de las ciudades intermedias de nuestro país, la posibilidad de poseer una vivienda digna es cada vez una expectativa con mayores dificultades de realización. Alto Comedero es un barrio ubicado al sudeste de la ciudad, que se origina en un plan de viviendas en el año 1986 y que para 2009 contaba con una población estimada de 185.000 habitantes (Bergesio y Golovanevsky, 2014:30), lo que representa más de 20 \% de la población total de la ciudad. Este barrio se ha desarrollado y crecido en la década de 1990 es decir, en la etapa de desarrollo del modelo neoliberal en la Argentina. Alto Comedero refleja, de manera paradigmática, la crisis de ese periodo porque se fue habitando con base en, fundamentalmente, migrantes internos desocupados y familias con trabajadores precarizados. El crecimiento de Alto Comedero es particularmente interesante por su magnitud sin precedentes en la provincia de Jujuy y es tan notable que se lo denomina comúnmente nueva ciudad. 
Movimientos sociales e institucionalización: la especificidad de... FERNANDA TORRES

La impronta de la OBTA se materializó en la manera como construyeron sus barrios y en la manera como disputaron el uso del suelo urbano: dejando de lado la especulación inmobiliaria y el individualismo propio del esquema meritocrático liberal que sujeta las posibilidades de las personas a la capacidad de compra en el mercado (la lógica del mercado, según Abramo).

Pero es necesario aclarar que el territorio que construyó la organización a partir de su entramado barrial no se constriñó solo a éste; por el contrario, a raíz de la capacidad de movilización de personas, recursos, soluciones y símbolos que la organización poseía, acumuló a nivel provincial un lugar central como sujeto político de activación y resolución de demandas, mayormente provenientes de los sectores populares informales, pero que también supo incluir otros actores, como trabajadores formales y medianos empresarios. También facilitó reposicionamientos simbólicos, étnicos y clasistas, al posibilitar que los indígenas y los pobres de Jujuy pudieran tener acceso simbólica y materialmente al uso del centro de la ciudad, al construir su Sede en una de las calles céntricas de San Salvador. Era imposible no verlos: su sede, su colegio, su pileta de natación cubierta y climatizada, sus consultorios externos, su radio comunitaria, se encontraban en el medio de la ciudad capital, entre transeúntes de clase media, profesionales y políticos y miembros de la gente bien jujeña, expresión referida por un miembro de la organización.

En segundo lugar, la identidad de la organización se amalgamaba en esta concepción territorial, se identificaban como tupaqueros porque compartían un espacio propio simbólico y material; compartían una forma de concepción del trabajo, de la militancia, de la convivencia barrial. Comenzaron a construir otra subjetividad, anclada en la potencialidad del trabajo colectivo, la responsabilidad y la solidaridad. También, nutrida de una fuerte disciplina y bajo una organización notablemente verticalista en la cual, si bien se realizaban grandes asambleas, la voz primordial en ellas era habitualmente la de las personas con fuertes liderazgos.

Sin duda, estas nuevas subjetividades transformadoras se encontraban claramente asociadas a una forma de liderazgo territorialmente situado: Milagro Sala. Una mujer jujeña, pobre, indígena, que pudo construir, desde esa identidad individual, una identidad colectiva a su imagen. Identidad colectiva ligada a acciones de disputa en torno a la definición de la jujeñidad, hegemónicamente asociada a lo blanco y lo urbano (Gaona y Ficoseco, 2012).

En tercer lugar, derivado de (y reforzando) lo anterior, el territorio de la OBTA puede concebirse como el dispositivo de producción y reproducción de procesos de socialización política. Los hombres y mujeres, adultos y jóvenes que se incorporaron a la Tupac no solo encontraron la resolución de muchas de sus demandas (de vivienda, de salud, educativas, laborales, culturales), sino que se sumaron a una construcción colectiva que involucraba afectos, códigos comunes de comprensión del mundo, de tramitación de diferencias y disputas. Nuevas relaciones sociales, nuevos valores y nuevas mediaciones para concebirse en tanto un nosotros político y potente para la acción colectiva extracotidiana, bajo grandes movilizaciones y eventos públicos. Pero también en eventos y situaciones cotidianas de convivencia y construcción día a día de la organización en sus barrios, en sus copas de leche, en sus fábricas y escuelas. 
Frente a un contexto hostil, frente al mercado económico y político dominante que sistemáticamente los invisibiliza como sujetos de derecho, que los denigraba como sujetos laborales y que los silenciaba como sujetos políticos, la posibilidad de la construcción política abierta desde la propia agencia, puede ser considerada el primer gran paso para una nueva subjetividad y socialización política transformadora en un territorio redefinido y construido en disputa con esos otros territorios de la política, de la economía y de la sociedad jujeña capitalista, blanca y urbana.

En cuarto y último lugar, referenciamos dos procesos de institucionalización que permiten comprender la base territorial de los mismos, que acompaña el argumento principal de este trabajo: que las instituciones de los movimientos socioterritoriales son construidas en y desde el territorio apropiado.

El proceso de institucionalización que protagonizó la OBTA a partir del 2013 estuvo centrado en la creación de un partido político como herramienta electoral, el Frente Unidos y Organizados (FUyO). Este último eje puede ser considerado central, puesto que propone el tránsito del territorio político propio, producido, apropiado y controlado al territorio político de las instituciones dominantes en el régimen político poliárquico. Del territorio de las movilizaciones, del poder popular, de la ocupación de las calles y plazas, de la construcción de barrios, de escuelas y de fábricas con reglas de funcionamiento y pautas de intercambio construidos desde la propia organización, al espacio de la representación electoralista, con su lógica y reglas propias.

En otro trabajo se analizó el desempeño electoral del FUyO en las contiendas electorales de 2013 y 2015 (Autor, 2019), puesto que se constata una caída muy fuerte en la cantidad de votos que obtuvo el partido entre una elección y otra. Pero lo que interesa resaltar aquí es que la base de legitimación y acumulación política que se expresó en el FUyO provino del desarrollo de la militancia territorial de la Tupac y que este proceso de institucionalización formal dependía por completo del éxito de mantener en pie el territorio propio. El entramado territorial de la militancia de la organización era el que se valoraba como propio, intransferible y único, lo que se puede constatar en varios testimonios expresados en una asamblea general de la OBTA, realizada el 29 de octubre de 2015 en el patio interno del colegio secundario Olga Aredes, ubicado frente a la sede de la Tupac (Figura 2): "La Red fracasó, no hicieron un esquema de desarrollo territorial a la altura de las circunstancias"; "La campaña, la militancia la puso toda la Tupac, que es la que está en todos los barrios y en todos los rincones de la provincia”. 


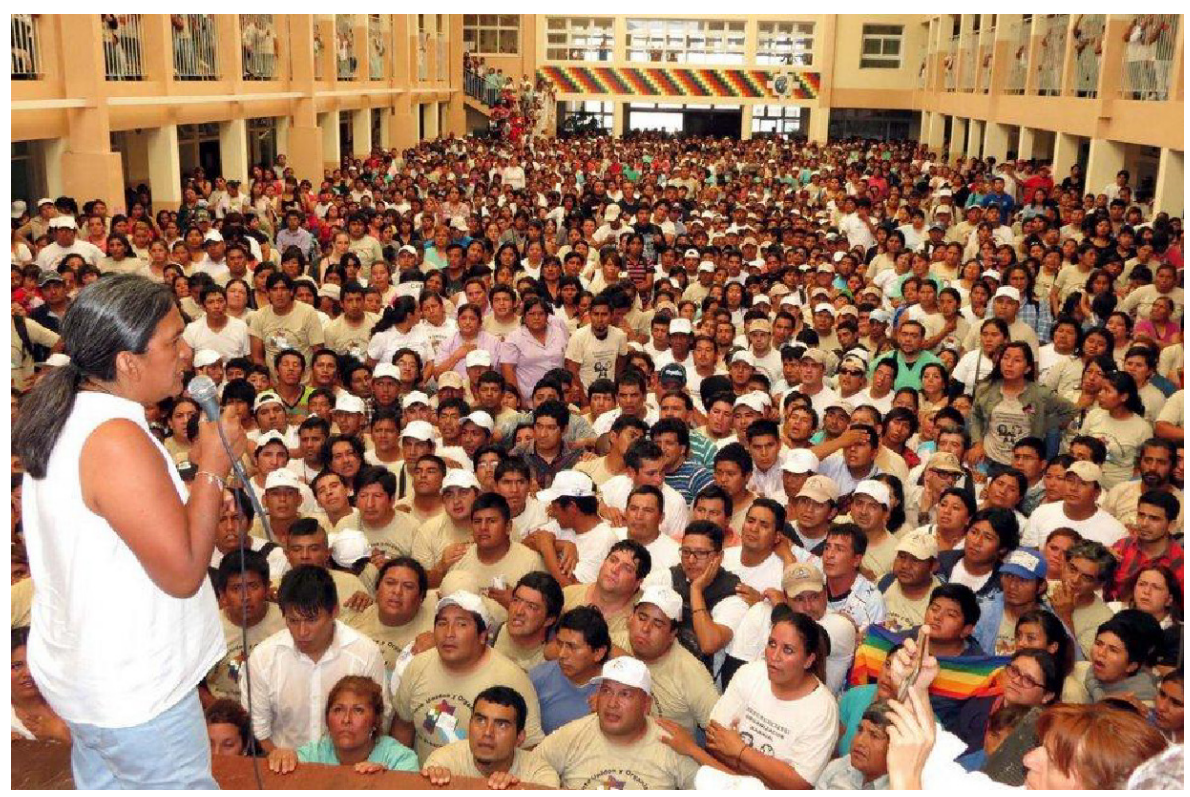

Figura 2. Asamblea de la Organización Barrial Tupac Amaru, presidida por Milagro Sala, en el Colegio Secundario Olga Arédez, S. S. de Jujuy. 29/10/2015. Fuente: http://www.eltribuno.info/ gobernar-todos-n632971

Esta expresión nativa, que refiere a estar en todos los barrios, es lo que aquí analizamos como el desarrollo territorial barrial de la OBTA, que en Jujuy se inscribe en un conjunto de instituciones laborales, educativas, deportivas, de la salud, del esparcimiento y de la información. Todas ellas bajo un mismo sentido: las prácticas territoriales de la Tupac proponen la desmercantilización de lo que consideran derechos conquistados, con el compromiso de dejar de entenderlos como servicios con valor de cambio. Así lo expresaba una entrevistada:

Nosotros somos de clase pobre, porque muchas veces nos cerraron la puerta con eso que "tenés que pagar". Para nosotros tiene que ser todo igual, y le queremos enseñar a la gente que siempre tuvo que ser así, que no tenías que pagar para entrar a una pileta a bañarte, nosotros no la teníamos esa plata. No teníamos la salud que es gratis, los medicamentos gratis, nosotros le brindamos y le enseñamos a esta gente que sí puede hacerlo. (Laura, integrante del Grupo de Género y responsable del área de Derechos Humanos, S.S. de Jujuy. Abril de 2015).

En el ya mencionado barrio Alto Comedero es donde la organización llegó a desplegar con mayor intensidad su otro territorio. Le llamaron el cantri5 de la Tupac: claramente diferenciado su perímetro y con sus casas todas iguales, en el interior del barrio construyeron una escuela y una guardería infantil, un polideportivo y un parque acuático con la pileta más grande de todo el noroeste argentino (Figura 3), un centro cultural (que contaba incluso con un cine), un centro de salud, el Centro Modelo Integral de Rehabilitación (CEMIR), una fábrica textil, una de bloques, una de muebles de caño, una metalúrgica (Figura 4) y otros emprendimientos. 


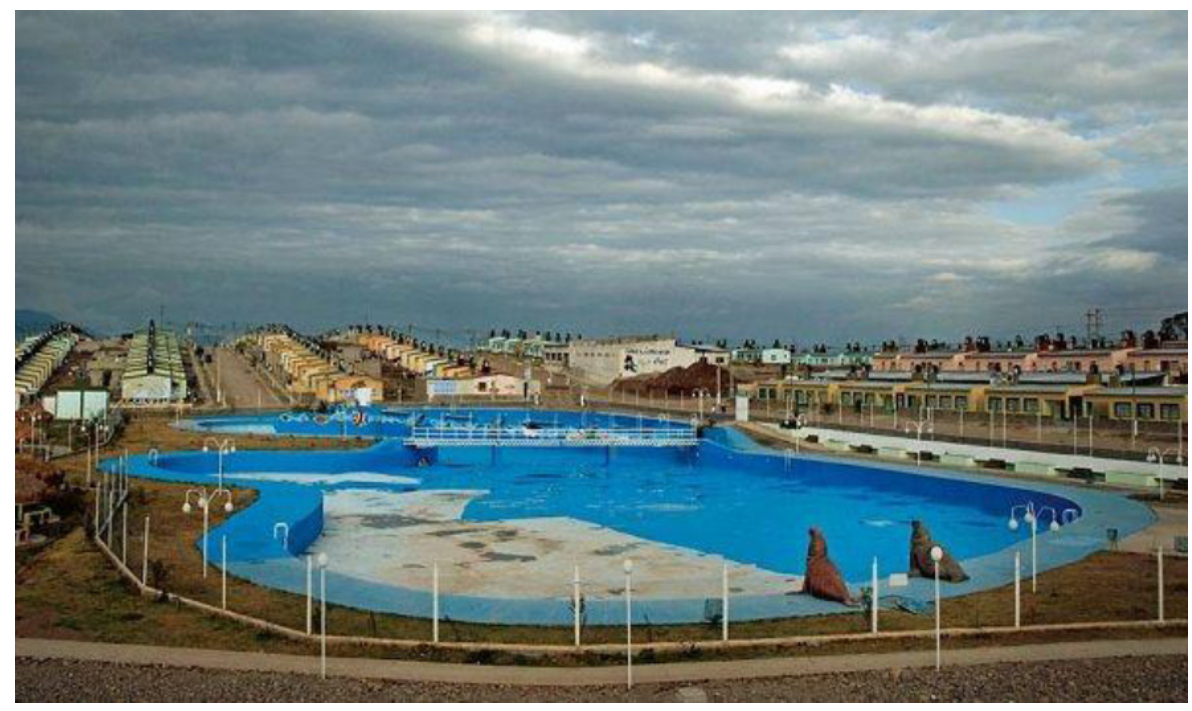

Figura 3. Parque acuático, Barrio de la Organización Barrial Tupac Amaru en Alto Comedero, S. S. de Jujuy. Fuente: http://www.taringa.net/post/imagenes/13364422/Fotos-del-barrio-TupacAmaru--S-S-de-Jujuy.html

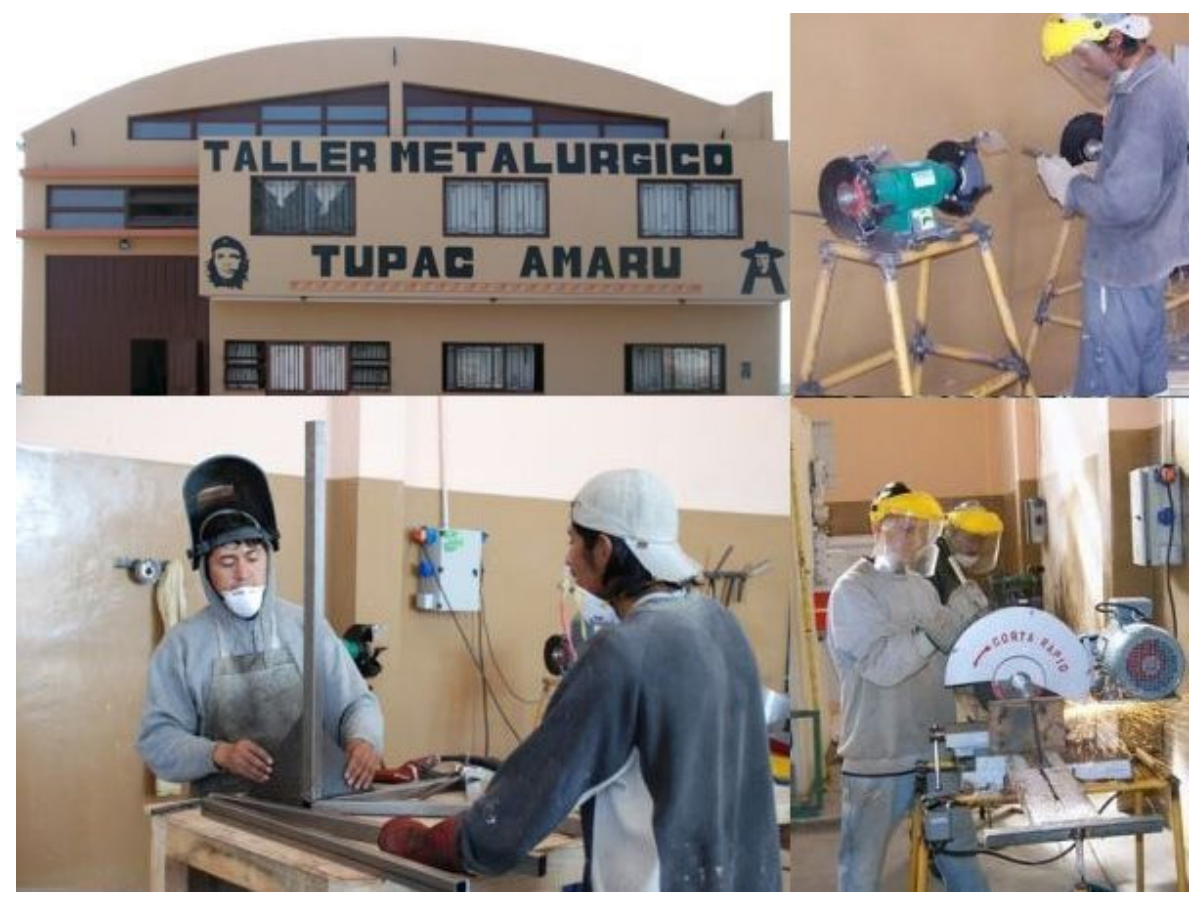

Figura 4. Fábrica metalúrgica de la Organización Barrial Tupac Amaru, S. S. de Jujuy. Fuente: http:// www.taringa.net/post/imagenes/13364422/Fotos-del-barrio-Tupac-Amaru-S-S-de-Jujuy.html

Todos espacios territorializados, construidos y gestionados por la organización cuyos miembros convivían y compartían sus espacios. La territorialidad no solamente es funcional, sino también, afectiva. La organización reconstruyó la vida social en ese territorio que devino en lugar, en espacio territorializado y vivido (Hiernaux y Lindón, 2004). 
Movimientos sociales e institucionalización: la especificidad de... FERNANDA TORRES

Algunos ejemplos de las actividades y áreas que fue asumiendo la organización a medida que crecía y se diversificaba, dan cabal cuenta de esta dimensión afectiva, cultural y con fuerte contenido simbólico.

Por un lado, es de resaltar el templo que se construyó en el barrio, una réplica del Templo Inca del Tiwanaku, en el que se realizaban diversas ceremonias tradicionales consideradas sagradas por los pueblos originarios de la región. Pero junto con esta práctica, que busca respetar y reivindicar tradiciones milenarias, la organización supo también colocarse en un rol progresista e innovador: brindó espacio, recursos y contención para que sus integrantes homosexuales, bisexuales y transexuales tuvieran un programa de radio y un llamado Grupo de Diversidad de Género que comenzó a realizar muchas actividades, entre las cuales sobresalen la organización de la Marcha por el Orgullo Gay, los días 28 de junio de cada año, con la construcción de carrozas y desarrollo del desfile por calles céntricas de la ciudad.

También podemos señalar las actividades relacionadas con la cultura, como la construcción de un cine en el barrio, un centro cultural en el que se desarrollan desde espectáculos musicales y teatrales hasta cumpleaños infantiles, la gestión de una radio comunitaria propia, innumerables polideportivos diseminados por diferentes barrios en la ciudad de San Salvador y en localidades del interior de la provincia, en los cuales se desarrollaba y fomentaba el ejercicio y la práctica de diversos deportes.

En este apretado y no exhaustivo relato, no puede dejar de analizarse la ya mencionada construcción de piletas de natación (Figura 3) con acceso gratuito, decisión con un alto valor simbólico en una región que durante el verano suele soportar temperaturas de más de $40^{\circ}$ y donde las pocas piletas municipales públicas históricamente han sido vedadas al acceso de los niños y las niñas de los sectores populares.

$\mathrm{Al}$ construir barrios e instituciones territoriales mediante las que se configura como una identidad política, laboral, social y de género no solo se construyen territorios per $s e$, sino que estos tienen una proyección simbólica clave: suponen espacios identitarios y de sociabilización y pertenencia política.

Como ya dijimos, la organización construyó varios centros educativos en los niveles primario, secundario y terciario. En toda esta experiencia, con énfasis en las dos últimas, el movimiento realizó cambios en las reglas, temas y contenidos pedagógicos impartidos en sus centros educativos para adecuarlos a sus objetivos y valores, a su proyecto político. Por ejemplo, abrieron en el nivel secundario una asignatura llamada autoestima, porque interpretaron que uno de los objetivos de su proyecto educativo era contribuir a formar subjetividad política y legitimidad de la militancia. En palabras de uno de los profesores y miembro de OBTA:

Entonces, en las reuniones de profesores, de porteros, de preceptores, se baja línea de la concepción: "si usted me pierde alumnos, los sale a buscar; si usted maltrata un alumno, no es este su lugar." Nosotros necesitamos que el compañero [alumno] se convierta en dos años de estudio en un compañero de ruta; no sé si será tupaquero, pero mire, con que cuando salgamos nosotros a caminar a la calle nos salude, nos reconozca y diga, "che, sigan bien, sigan adelante", ya hemos ganado un compañero que nos conoce de adentro. (Juan Cruz, miembro del área de Educación. S. S. de Jujuy. Abril de 2015). 
Movimientos sociales e institucionalización: la especificidad de... FERNANDA TORRES

Las familias, las personas que habitan, construyen y recorren dichas instituciones en y desde sus territorios, no solo lo hacen en tanto que trabajadores/as, mujeres, estudiantes, niño/as o indígenas, sino que la multiplicidad de articulaciones identitarias puede intentar resumirse en la idea de la construcción de un otro espacio de la política (Tapia, 2008). Producción de otra ciudadanía que habilita la representación ya no anclada en ideas universalistas de los derechos y deberes ciudadanos, sino en derechos y deberes ciudadanos particulares y diferenciables. Se puede dar el paso hacia la representación partidaria (como se intentó con el FUyO), pero el lazo de la representación no deja de tener una base de sustentación territorial, atendiendo a la definición del concepto territorio que fue desplegado anteriormente en este trabajo y que permite comprender una forma de participación ciudadana desde la interpelación identitaria, política y estratégica asociada a un territorio apropiado y en el que se despliega el poder popular.

\section{Ciudadanías territorializadas como cierre y como apertura}

Es posible revisar la noción de ciudadanía, reconociendo dos aspectos: el formal, que refiere a la pertenencia a la comunidad política (durante buena parte de la historia concentrada en los límites del Estado-nación) y el sustantivo, vinculado a la distribución de derechos, deberes y recursos implicados en el aspecto formal y que se ejercitan de hecho.

James Holston (2009) identifica nuevas prácticas ciudadanas en torno a tres procesos. En primer lugar, un nuevo tipo de participación en la esfera pública, donde las necesidades en términos de derechos son articuladas en sus prácticas urbanas. En segundo lugar, una novedosa comprensión de las bases de estos derechos y su dignidad como ciudadanos. Y, por último, la transformación de la relación entre ciudadanos y Estado, habilitando la generación de nuevos marcos legales y de nuevas instituciones participativas. Si retomamos el primer proceso, podemos comprender que la base de los movimientos socioterritoriales urbanos para construir sus demandas es el territorio. Pero es necesario aclarar que no es cualquier concepción de territorio la que permite validar esta afirmación, sino el territorio entendido como una relación social que plasma en el espacio las relaciones de poder.

Para finalizar el recorrido analítico planteado en este trabajo, creemos que es posible identificar ciudadanías territorializadas cuando dichas demandas en torno a necesidades y derechos se constituyen en relación con un territorio, por lo que proponemos repasar dichas dimensiones a la luz de este recorte específico y atendiendo al caso de referencia estudiado.

El hábitat y la residencia urbana, en el caso de la OBTA, constituye la base de la movilización, pero debe quedar claro que la vivienda es la síntesis simbólica de la construcción de un territorio urbano colectivo y no solo una salida individualizante. Supone la modalidad popular de urbanización, bajo una lógica asociada al trabajo comunitario, colaborativo, autogestivo, que entra en pugna con la lógica propia del mercado para habilitar el acceso a suelo urbano sólo para quienes pueden comprarlo. Además, la vivienda nunca es una demanda aislada, viene acompañada de una cadena de sentidos y valores que acompañan otra forma de vivir y de convivir: esto tiene relación con la segunda dimensión. 
Por supuesto, en la demanda por el derecho a la ciudad, se condensa la disputa por el variado y múltiple abanico de elementos centrales para comprender y definir nuestra vida social: trabajo, ocio, familia, libertades, espacio público, participación, etc. La clave de los movimientos socioterritoriales es poder incorporar dichos elementos en la definición de otros territorios, donde la vida puede desarrollarse por diferentes canales, las relaciones sociales se configuran a través de modalidades divergentes respecto a las hegemónicas, propias del capital y sus formas de reproducción social. Pensar el derecho a la ciudad de este modo implica una redefinición de la comunidad política de referencia y del sentido de las prácticas y pertenencias ciudadana, en una clave sustantiva.

Ahora bien, si planteamos que las ciudadanías pueden ser un cierre es porque, de acuerdo con nuestro argumento alrededor de este tipo de experiencias ciudadanas en torno a los movimientos socioterritoriales, las instituciones son definidas territorialmente $\mathrm{y}$, por ende, dependen de las relaciones de poder que se ejerzan sobre ese espacio, para garantizar su apropiación y su regulación institucional. Como fue sugerido, la contingencia política que nace de las correlaciones de fuerza que sostienen dicho poder siempre está vigente.

Pero también pueden delinearse como apertura, pueden pensarse como espacios de politización popular legítima. Construcción de ciudadanías territorializadas, potentes y transformadoras que permitan volver al dilema de la relación integral entre estrategia e identidad que deben resolver los movimientos sociales políticamente orientados para no perder su autonomía, en estos casos garantizada por su control territorial y, a la vez, no abandonar su orientación al cambio social y la transformación de los límites del sistema en el que actúan.

En los casos de los movimientos socioterritoriales urbanos, el cambio hace eje en la disputa por el territorio urbano y transformación de la manera mediante la cual concebimos la ciudad, generando prácticas y sentidos en base a criterios de desmercantilización y preeminencia de los valores de uso en torno al acceso al suelo y hábitat urbano $\mathrm{y}$ anclando dichas prácticas y valores en instituciones territorializadas. 


\section{Q Bibliografía}

》 Abramo, P. (2003). La teoría económica de la favela: cuatro notas sobre la localización residencial de los pobres y el mercado inmobiliario informal. Revista Ciudad y Territorio: Estudios territoriales, 136-137, 273-294.

» Bergesio, L. y Golovanevsky, L. (2014). Las ciudades y sus muros de cristal. Ajuste neoliberal en una experiencia del noroeste argentino. Economía, Sociedad y Territorio, 14(44), 1-48.

»Bringel, B. y Falero, A. (2016). Movimientos sociales, gobiernos progresistas y estado en américa latina: transiciones, conflictos y mediaciones. Caderno $\mathrm{Crh}$, 29(3), 27-45.

»Castells, M. (1986). La ciudad y las masas. Sociología de los movimientos sociales urbanos. Madrid: Alianza.

»Deleuze, G. y Guattari, F. (2002) Mil Mestas: Capitalismo y esquizofrenia. España: Pre-textos.

»Dinerstein, A. et al. (2013). Movimientos Sociales y Autonomía Colectiva. Buenos Aires: Capital Intelectual.

》Elden, S. (2013). The birth of territory. London: University of Chicago Press.

»Fernandes Mançano, B. (2005). Movimientos socio-territoriales y movimientos socio-espaciales. OSAL, 16, 273-283.

»Gaona, M. y Ficoseco, V.S. (2012). La jujeñidad cuestionada: Acciones colectivas que desafían las normas y los márgenes. Revista Question, 1(35), 100-113.

» García Linera, A. (2016). Democracia, Estado, Nación. La Paz: Vicepresidencia del Estado Plurinacional de Bolivia.

» Grimson, A. Ferraudi, M. C. y Segura, R. (Comp.). (2008). La vida política en los barrios populares de Buenos Aires. Prometeo: Buenos Aires.

" Haesbaert, R. (2004). O mito da desterritorialização. Do "Fim dos Territorios" a multiterritorialidade. Río de Janeiro: Bertrand Brasil.

" Hale, C. (2006). Activist Research versus Cultural Critique: Indigenous Land Rights and the contradictions of Politically Engaged Anthropology. Cultural Anthropology, 21(1), 96-120.

» Halvorsen, S., Fernandes, M.B. y Torres, F. (2019). Mobilising Territory: Socioterritorial Movements in Comparative Perspective. Annals of the American Association of Geographers. Recuperado de: https://doi.or $\mathrm{g} / 10.1080 / 24694452.2018 .1549973$.

" Halvorsen, S. (2018). Decolonising territory: Dialogues with Latin American knowledges and grassroots politics. Progress in Human Geography. DOI: 10.1177/0309132518777623.

»Hiernaux, D. y Lindón, A. (2004). Desterritorialización y reterritorialización metropolitana: la ciudad de México. Documents d'Anàlisi Geogràfica, 44, 71-88.

» Holston, J. (2009). La ciudadanía insurgente en una era de periferias urbanas 
Movimientos sociales e institucionalización: la especificidad de... FERNANDA TORRES

globales. Un estudio sobre la innovación democrática, la violencia y la justicia en Brasil. En: G. Delamata (Comp.), Movilizaciones sociales: ¿Nuevas ciudadanías? (pp. 145-165). Buenos Aires: Biblos.

»Lefebvre, H. (2013). La producción del espacio. Madrid: Capitán Swing.

» Lopez Maya, M. (2003). Movilización, institucionalidad y legitimidad en Venezuela. Rev. Venez. de Econ. y Ciencias Sociales, 9(1), 211-226.

" Manzanal, M., Azeno, M. y Nussbaumer, B. (Comp.). (2007). Territorios en construcción, Actores, tramas y gobiernos, entre la cooperación y el conflicto. Buenos Aires: Edit. CICCUS.

»Marshall, T.H. (1997). Ciudadanía y Clase social. Reis, 79, 297-344.

»Melucci, A. (1986). Movimenti sociali e sistema político. Milan: Franco Angelli.

» Merklen, D. (2005). Pobres ciudadanos. Las clases populares en la era democrática (Argentina 1983-2003). Buenos Aires: Gorla.

» Munck, G. (1995). Algunos problemas conceptuales en el estudio de los movimientos sociales. Revista Mexicana de Sociología, 57(3), 17-39.

» Natalucci, A. y Pagliarone, M. F. (2013). Revisitando los conceptos de lo social y lo político: movimientos sociales, procesos de democratización y nuevas institucionalidades. Revista Andina de Estudios Políticos, 3(2),77-98.

» Natalucci, A. y Pérez, G. (2015) La imaginación institucional. Movimientos Sociales y Estado en Argentina (2003-2015). III Congreso Latinoamericano y Caribeño de Ciencias Sociales. Quito, Ecuador.

» O’Donnell, G. (1997). Otra institucionalización. En: G. O’Donnell, Contrapuntos (pp. 305-330). Buenos Aires: Paidós.

» Offe, C. (1992). Reflexiones sobre la autotransformación institucional de la actividad política de los movimientos. Modelo provisional según estudios. En: R. J. Dalton y M. Kuechler (Comps.), Los nuevos movimientos sociales: un reto al orden político (pp. 315-340). Valencia: Edicions Alfons el Magnanim.

»Procacci. G. (1999). Ciudadanos pobres, la ciudadanía social y la crisis de los Estados de bienestar. En: S. García y S. Lukes (Eds.), Ciudadanía: justicia social. identidad y participación, 15-44. Madrid: Siglo XXI.

»Raffestin, C. (1993) Por uma geografía do poder. Sao Paulo: Editora Ática.

》 Reyes, A. (Ed.). (2012). Special Issues: Autonomy and Emancipation in Latin America. South Atlantic Quarterly 111(1), s/n.

» Rossi, F. (2015). Beyond Clientelism: The Piquetero Movement and the State in Argentina. En: P. Almeida y A. Cordero Ulate (Eds.), Handbook of Social Movements across Latin America (pp. 117-128). Nueva York: Springer.

》Santos, M. (1985). Espaço e Método. São Paulo: Nobel.

"Santos, M. (1996). A Natureza do Espaço. São Paulo: Hucitec.

» Schneider, S. y Tartaruga, I. (2006). Territorio y enfoque territorial: de las referencias cognitivas a los aportes aplicados al análisis de los procesos sociales rurales. En: M. Manzanal, G. Neiman y Lattuada, M. (Org.), Desarrollo Rural. Organizaciones, Instituciones y Territorio, 71-102. Buenos Aires: Ciccus.

"Schuttenberg, M. (2012). Los movimientos sociales "nacionales populares" 
en la etapa kirchnerista: una revisión crítica de la bibliografía sobre el período. Intersticios: Revista Sociólogica de Pensamiento Crítico, 6(2), 191-207.

"Sehtman, A. (2009). La reproducción política de la precariedad urbana. El caso de la Villa 31 (1996-2007). Tesis de Maestría en Políticas Públicas y Gerenciamiento del Desarrollo, Universidad Nacional de San Martín/ Georgetown University. Recuperado de: https://repository.library.georgetown. edu/bitstream/handle/10822/553259/sehtmanyCavoClaudioAlejandro. pdf? sequence $=1$ \&isAllowed $=y$

"Souza Lopes de, M. (2001). 0 território: sobre espaço e poder, autonomia e desenvolvimento. En: I. Elias de Castro, P. Da Costa Gomes y R. Lobato Azevedo Corrêa (Coords.), Geografia: conceitos e temas, 77-116. Rio de Janeiro: Bertrand Brasil.

»Souza Lopes de, M. (2011). Autogestión, “autoplaneación”, autonomia: actualidad y dificultades de las prácticas espaciales libertarias de los movimientos urbanos. En: G. Calderón y E. León (Orgs.), Descubriendo la espacialidad social desde América Latina: Reflexiones desde La geografía sobre el campo, la ciudad y el medio ambiente (Cómo pensar la geografía, 3). Ciudad de México: Itaca.

»Svampa, M. (2016) Debates Latinoamericanos. Indianismo, Desarrollo, Dependencia, populismo. Buenos Aires: Edhasa.

»Tapia, L. (2008). Movimientos sociales, movimientos societales y los no lugares de la política. En: L. Tapia, Política Salvaje, 53-68. La Paz: CLACSO, Muela del Diablo Editores y Comuna.

" Tarrow, S. (1997). El poder en movimiento: los movimientos sociales, la acción colectiva y la política. Madrid: Alianza.

» Tilly, Ch. (2010). Los movimientos sociales, 1768-2008. Desde sus orígenes a facebook. Barcelona: Crítica.

» Torres, F. (2016). Organización Barrial Tupac Amaru en San Salvador de Jujuy: ¿Un Movimiento Social Urbano?. Revista Question, 1(49), 415-430. Recuperado de: http://perio.unlp.edu.ar/ojs/index.php/question/article/view/3064/2610

" Torres, F. (2018). Modalidades mixtas de producción de hábitat por parte de sectores populares: organizaciones sociales y Estado. El caso de la Organización Barrial Tupac Amaru en Jujuy-Argentina. OBETS, Revista de Ciencias Sociales, 13, Extra 1, 411-438. DOI:10.14198/OBETS2018.13.1.15

» Torres, F. (2019). Proceso de territorialización de la Organización Barrial Tupac Amaru: cooperativas, barrio y política. Revista Estudios Socioterritoriales, 25, 1-17. DOI: https://doi.org/10.37838/unicen/est.25-023

》Zibechi, R. (2008). Territorios en resistencia. Cartografía política de las periferias urbanas latinoamericanas. Buenos Aires: lavaca editora.

\section{Fernanda Valeria Torres / ftorres@fahce.unlp.edu.ar} Investigadora del CONICET y profesora ordinaria de la UNLP. Licenciada en Sociología y Doctora en Ciencias Sociales (UNLP) con lugar de trabajo en el Instituto y de Investigaciones en Humanidades y Ciencias Sociales. Sus temas de investigación se ubican en el campo de la sociología política y los estudios de movimientos sociales y socioterritoriales urbanos. Es autora de diversos artículos y capítulos de libros sobre dichas temáticas. 